\title{
Upaya Represif dan Preventif dalam Penegakan Hukum terhadap Pelanggaran Lalu lintas oleh Kendaraan Pengangkut Suporter PSIM
}

\section{Andi Jafits Luster Romadhon}

Program Studi Hukum, Fakultas Hukum, Universitas Muhammadiyah Yogyakarta

Email : andi.jafits.2016@law.umy.ac.id;

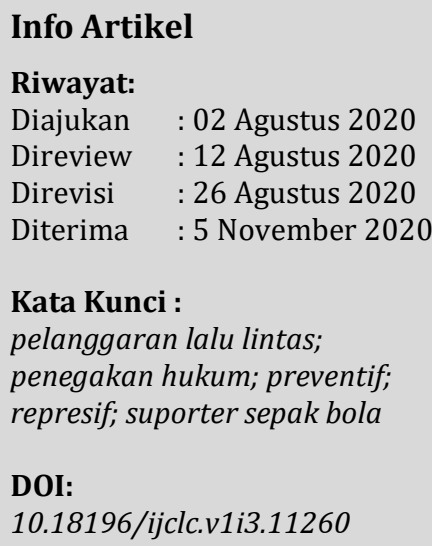

\begin{abstract}
Abstrak
Sepak bola dan suporter merupakan satu kesatuan yang tidak dapat dipisahkan. Faktanya suporter sepak bola seringkali menunjukkan sikap fanatis yang berlebihan terhadap tim yang didukungnya melalui berbagai tindakan negatif seperti merusak fasilitas umum dan melakukan pelanggaran lalu lintas. Hal demikian terjadi juga pada suporter PSIM Yogyakarta dengan berfokus pada pelanggaran lalu lintas terhadap kendaraan pengangkut. Lebih lanjut tulisan ini akan membahas tentang upaya preventif dan upaya represif terhadap penegakan hukum suporter PSIM yang dilakukan melalui penelitian yang bersifat yuridis empiris. Berdasarkan hasil penelitian diketahui bahwa penegakan hukum terhadap pelanggaran lalu lintas oleh kendaraan pengangkut suporter sepak bola dilakukan oleh pihak kepolisian baik secara preventif maupun represif. Upaya preventif dilakukan pihak Satlantas Polresta Yogyakarta dengan cara memberikan pengawalan terhadap konvoi suporter dan menempatkan anggotanya di titik-titik yang dilalui suporter PSIM. Sedangkan upaya represif yang dilakukan dengan penindakan, baik melalui teguran dan penilangan.
\end{abstract}

\section{Pendahuluan}

Suporter merupakan salah satu elemen sepak bola yang tak kalah menarik untuk ditonton dan diperbincangkan. Kehadiran para suporter tak hanya mampu membuat stadion menjadi lebih hidup dan semarak. Bahkan, melalui beragam aksi kreatifnya, para suporter mampu memberikan suntikan semangat bagi para kesebelasannya. Tanpa suporter, permainan sepak bola akan layu dan kering. ${ }^{1}$ Suporter datang ke stadion untuk mendukung timnya dan tiada lelah untuk memberikan dukungan kepada tim kesayangannya dengan cara bernyanyi maupun membuat suatu koreografi. Kehadiran para suporter membawa dampak positif, yaitu dapat menambah semarak pertandingan tersebut, sehingga sepak bola di Indonesia mempunyai nilai yang baik di mata dunia.

Suporter Indonesia bisa dikatakan merupakan suporter yang sangat fanatik dan merupakan salah satu suporter paling fanatik di dunia. Indonesia berada diurutan ke tiga setelah Inggris dan juga Argentina. ${ }^{2}$ Namun dari kefanatikannya tersebut, masih tercoreng oleh kejahatan segelintir oknum yang masih kurang memperhatikan peraturan lalu lintas ketika berangkat maupun pulang dari stadion.

Salah satu kejahatan dilakukan oleh Suporter PSIM Yogyakarta, contohnya seperti kerusuhan, baik rusuh terhadap sesama suporter tim lain maupun rusuh terhadap aparat kepolisian, perusakan fasilitas umum, dan tindakan-tindakan anarkis lainnya. Hal inilah yang membuat masyarakat menjadi cemas dan takut terhadap kehadiran suporter sepak bola, dan mempunyai pandangan yang negatif

\footnotetext{
${ }^{1}$ Islafatun, Nor. (2014). Arek Bonek: Satu Hati Untuk Persebaya. Yogyakarta: Notebook. h. 5.

${ }^{2}$ Hapsari, Indria dan Wibowo, Istiqomah. (2015). Fanatisme Dan Agresivitas Supporter Klub Sepak Bola. Jurnal Psikologi. 8(1). h. 53.
} 
terhadap suporter. Selain itu masih ada saja oknum-oknum suporter PSIM yang mengabaikan peraturan yang sudah dibuat. Karena tujuannya dibuat hukum itu untuk keuntungan dan kelancaran bersama, bukan memiliki tujuan yang tidak dapat dicerna, yang lahir barangkali hanya karena, tradisi, kelambanan legislatif, atau kebutuhan untuk mengompromikan secara radikal berbagai macam tujuan berbeda dari kelompok-kelompok kepentingan yang ada. ${ }^{3}$

Hukum dalam hal ini sebagai sarana pemaksa yang melindungi warga masyarakat dari ancaman maupun perbuatan yang membahayakan diri serta harta bendanya. ${ }^{4}$ Seharusnya suporter PSIM sebagai warga negara yang baik, mematuhi peraturan hukum bukan melakukan hal yang melanggar hukum seperti contohnya melanggar lalu lintas yang dapat menyebabkan terhambatnya lalu lintas. Seperti yang dilansir dari platform media online Tirto.id $:^{5}$

Yogyakarta - Masalah menjadi runyam tatkala kabar suporter Persis yang tertahan di Prambanan ini sampai ke telinga spporter PSIM. Ditambah dengan berbagai bumbu provokasi di media sosial, sejumlah suporter dari arah Yogyakarta yang emosinya terpancing lantas berdatangan ke Prambanan melakukan 'sweeping' plat nomor AD petang harinya. Di beberapa titik, kerusuhan tak terhindarkan, termasuk di Kawasan depan Candi Prambanan. Fandy Gunawan (24), seorang warga yang tinggal di sekitar Candi Prambanan menceritakan di bentrok ini berpusat di sekitar Indomaret Prambanan yang letaknya tak jauh dari candi. "kedua kubu sempat bentrok di depan Indomaret Prambanan, selebihnya efek yang paling terasa kemacetan. Lalu lintas terhambat karena kejadian ini," keluhnya.

Jika melihat dari kasus di atas tersebut, para suporter itu tidak berperilaku tertib kepada sesama pengguna jalan, mereka melakukan sweeping yang dapat menyebabkan kemacetan sehingga lalu lintas menjadi terhambat. Pasal 105 Undang-undang No. 22 Tahun 2009 tentang Lalu Lintas dan Angkutan Jalan menjelaskan:

Setiap orang yang menggunakan Jalan wajib:

1. Berperilaku tertib; dan/atau

2. Mencegah hal-hal yang dapat merintangi, membahayakan Keamanan dan Keselamatan Lalu Lintas dan Angkutan Jalan, atau yang dapat menimbulkan kerusakan Jalan.

Selain itu disaat timnya akan bertanding, para suporter pergi secara bersama-sama atau konvoi, konvoi yang mereka lakukan ketika hendak berangkat ke stadion maupun pulang sehabis pertandingan tidak memperhatikan peraturan lalu lintas yang ada. Sebenarnya sudah dibuat jelas peraturannya Pasal 106 Ayat (4) Undang-undang No. 22 Tahun 2009 tentang Lalu Lintas dan Angkutan Jalan menjelaskan bahwa, setiap orang yang mengemudikan Kendaraan Bermotor di jalan wajib mematuhi ketentuan antara lain, rambu perintah atau larangan, marka jalan, isyarat lalu lintas, gerakan lalu lintas, berhenti dan parkir, peringatan dengan bunyi dan sinar, kecepatan maksimal/minimal dan/atau tata cara penggandengan dan penempelan dengan kendaraan lain.

Jika dilihat dari Undang-undang dan Pasal yang disebutkan di atas, dapat disimpulkan bahwa perbuatan yang dilakukan suporter tidaklah menunjukkan perbuatan sebagai warga negara yang baik yang mematuhi peraturan, sehingga dari perbuatan yang mereka lakukan itu berdampak kepada masyarakat sekitar jalan yang mereka lalui dan sesama pengguna jalan yang bukan bagian dari kelompok suporter. Mereka hanya mementingkan kepentingan kelompok mereka sendiri dan melupakan hak masyarakat sebagai sesama pengguna jalan.

Berdasarkan hal tersebut tulisan ini akan menjelaskan lebih lanjut bagaimana upaya preventif dan upaya represif dapat dilakukan dalam penegakan hukum yang berfokus pada pelanggaran lalu lintas oleh kendaraan pengangkut suporter PSIM.

\section{Rumusan Masalah}

\footnotetext{
${ }^{3}$ Cotterrell, Roger. (2016). Sosiologi Hukum. Bandung: Nusa Media. h. 99.

${ }^{4}$ Soekanto, Soerjono. (1982). Kesadaran Hukum dan Kepatuhan Hukum. Jakarta: Cv Rajawali. h. 59.

5 Tirto.id, "Ricuh PSIM vs Persis: Menjalar ke Prambanan Wartawan Jadi Korban", https://bit.ly/39dArDP , diakses pada hari Rabu 13 November 2019, Pukul 20.44 WIB.
} 
Bagaimana upaya represif dan preventif dalam penegakan hukum terhadap pelanggaran lalu lintas oleh kendaraan pengangkut suporter PSIM?

\section{Metode Penelitian}

Penelitian ini akan menggunakan penelitian hukum yuridis empiris. Permasalahan dalam penelitian ini akan dianalisis menggunakan bahan hukum (data sekunder) lalu dipadukan dengan data yang diperoleh di lapangan (data primer). Penulis mengumpulkan data melalui observasi secara langsung di lokasi dalam permasalahan yang akan diteliti dalam penelitian ini, yaitu di sekitar Jalan Abu Bakar Ali, Kotabaru yang dilalui supporter PSIM. Selain itu, penulis juga melakukan wawancara dengan narasumber dan responden. Adapun narasumber dalam penelitian ini adalah Iptu. Ragil Suwardi (KBO Lantas Polresta Yogyakarta). Sedangkan respondennya, yaitu Niko Anggari (Sekretaris Jenderal Brajamusti), AP, Y dan IY (Suporter PSIM) dan Pak Wira, tukang helm yang berjualan di sekitar Jalan Abu Bakar Ali, Kotabaru, sebagai masyarakat atau korban pengguna jalan yang dilalui supporter PSIM. Data yang dikumpulkan tersebut akan di analisis dan diolah secara kualitatif untuk mendapatkan jawaban atas permasalahan yang penulis teliti.

\section{Hasil Penelitian dan Pembahasan}

PSIM Yogyakarta memiliki basis suporter yang sangat banyak, khusus di wilayah Kota Yogyakarta saja suporter yang terdaftar mencapai 15.000 lebih. PSIM merupakan klub sepak bola tertua di Daerah Istimewa Yogyakarta. Suporter PSIM Yogyakarta sering disebut dengan Brajamusti yang kepanjangannya adalah Brayat Jogja Mataram Utama Sejati. ${ }^{6}$ Besarnya basis masa suporter PSIM tersebut membuat suporter PSIM tidak luput dari beragam aksi fanatisme. Fanatisme yang sering terjadi, antara lain menyanyikan yel-yel, membuat suatu koreografi, membawa bendera yang berukuran besar, ricuh dengan suporter tim lain dan melanggar lalu lintas.

Warga Negara Indonesia yang berada di wilayah hukum Indonesia harus patuh dan tunduk terhadap segala peraturan yang ada. Warga Negara Indonesia tidak mempunyai hak imunitas yang membuatnya kebal terhadap hukum, sekalipun itu seorang Presiden maupun suporter sepak bola. Berdasarkan penelitian yang dilakukan, ditemukan bahwa jenis pelanggaran yang paling banyak dilakukan suporter PSIM disajikan dalam tabel 1.

Pelanggaran lalu lintas oleh kendaraan pengangkut suporter PSIM yang telah disebutkan di atas dapat dijelaskan sebagai berikut:

a. Sepeda Motor Tidak Memenuhi Persyaratan Teknis dan Laik Jalan

Suporter PSIM yang menggunakan knalpot blombongan dapat membuat pengguna jalan lain merasa tidak nyaman di jalan karena suara bising yang dikeluarkan knalpot blombongan tersebut.

b. Kendaraan Bermotor Tidak Dipasang Plat Nomor Kendaraan

Dalam Pasal 68 ayat (1) Undang-undang Nomor 22 Tahun 2009 tentang Lalu Lintas dan Angkutan Jalan, menjelaskan:

"Setiap Kendaraan Bermotor yang dioperasikan di Jalan wajib dilengkapi dengan Surat Tanda Nomor Kendaraan Bermotor dan Tanda Nomor Kendaraan Bermotor".

Pasal tersebut menjelaskan bahwa setiap kendaraan bermotor yang dioperasikan di jalan wajib dilengkapi dengan STNK dan Plat Nomor, tidak terkecuali untuk kendaraan bermotor yang digunakan oleh supporter PSIM. Jika kendaraan bermotor tidak dilengkapi dengan plat nomor, maka akan di khawatirkan suporter PSIM melakukan tindak kejahatan dan polisi tidak bisa mencari identitas pelaku dari plat nomor.

\footnotetext{
${ }^{6}$ Hasil Wawancara dengan Niko Anggari, Sekretaris Jenderal Brajamusti, pada hari Senin 23 Desember 2019, pukul 20:29 WIB.
} 
Tabel 1. Data pelanggaran lalu lintas

\begin{tabular}{cl}
\hline No. & \multicolumn{1}{c}{ Jenis Pelanggaran } \\
\hline 1. & $\begin{array}{l}\text { Sepeda } \\
\text { memenuhi persyaratan teknis } \\
\text { dan laik jalan. }\end{array}$
\end{tabular}

2. Kendaraan bermotor tidak dipasangi tanda nomor kendaraan bermotor.

3. Tidak memiliki SIM.

Pidana kurungan paling lama 1 (satu) bulan atau denda paling banyak Rp250.000,00 (dua ratus lima puluh ribu rupiah).

Pidana kurungan paling lama 2 (dua) bulan atau denda paling banyak Rp500.000,00 (lima ratus ribu rupiah).

Pidana kurungan paling lama 4 (empat) bulan atau denda paling banyak Rp1.000.000,00 (satu juta rupiah).

Pidana penjara paling lama 1 (satu) tahun atau

4. Jalan beriringan atau konvoi yang dapat menyebabkan gangguan fungsi jalan.

5. Menerobos APILL. denda paling banyak Rp24.000.000,00 (dua puluh empat juta rupiah).

Pidana kurungan paling lama 2 (dua) bulan atau denda paling banyak Rp500.000,00 (lima ratus ribu rupiah).

Pidana kurungan paling lama 2 (dua) bulan atau

6. Kendaraan Tidak Dilengkapi STNK. denda paling banyak Rp500.000,00 (lima ratus ribu rupiah).

Pidana kurungan paling lama 1 (satu) bulan atau

7. Tidak memakai helm.

8. Berboncengan 3 orang menggunakan sepeda motor.

9. Membawa bendera berukuran besar yang dapat mengakibatkan gangguan konsentrasi dalam denda paling banyak Rp250.000,00 (dua ratus lima puluh ribu rupiah).

Pidana kurungan paling lama 1 (satu) bulan atau denda paling banyak Rp250.000,00 (dua ratus lima puluh ribu rupiah).

Pidana kurungan paling lama 3 (tiga) bulan atau denda paling banyak Rp750.000,00 (tujuh ratus lima puluh ribu rupiah).

mengemudi di jalan.

10. Bersikap anarkis di jalan terhadap pengendara lain yang tidak mau memberikan jalan yang mengakibatkan Pidana penjara paling lama 2 (dua) tahun atau denda paling banyak Rp4.000.000,00 (empat juta rupiah). kerusakan kendaraan.

\section{Sumber: KBO Lantas Polresta Yogyakarta}

c. Tidak Memiliki SIM

Jenis pelanggaran lalu lintas ini, paling banyak dilakukan oleh suporter PSIM usia 13 sampai 18 tahun yang masih duduk di bangku sekolah, yang dimana usia mereka masih terlalu dini untuk mendapatkan SIM. Pasal 77 ayat (1) Undang-undang Nomor 22 Tahun 2009 tentang Lalu Lintas dan Angkutan Jalan, menyebutkan:

"Setiap orang yang mengemudikan Kendaraan Bermotor di Jalan wajib memiliki Surat Izin Mengemudi sesuai dengan jenis Kendaraan Bermotor yang dikemudikan”.

d. Jalan beriringan atau konvoi yang dapat menyebabkan gangguan fungsi jalan

Pasal 28 ayat (1) Undang-undang Nomor 22 Tahun 2009, menjelaskan:

"Setiap orang dilarang melakukan perbuatan yang mengakibatkan kerusakan dan/atau gangguan fungsi jalan". 
Berdasarkan isi Pasal 28 ayat (1) yang sudah dijelaskan di atas, konvoi yang dilakukan oleh suporter PSIM itu sangat jelas menyebabkan gangguan terhadap fungsi jalan sehingga menyebabkan kemacetan. Dengan demikian, konvoi yang dilakukan oleh suporter PSIM tersebut merupakan suatu pelanggaran lalu lintas.

e. Menerobos APILL

Suporter PSIM yang mengikuti konvoi, karena mereka bergerombol dan merasa kuat, maka untuk melanggar jenis pelanggaran ini mereka seringkali melakukannya.

Pasal 106 ayat (4), menjelaskan:

Setiap orang yang mengemudikan Kendaraan Bermotor di Jalan wajib mematuhi ketentuan:

a. Rambu perintah atau rambu larangan;

b. Marka jalan;

c. Alat Pemberi Isyarat Lalu Lintas;

d. Gerakan Lalu Lintas;

e. Berhenti dan parkir;

f. Peringatan dengan bunyi dan sinar;

g. Kecepatan maksimal atau minimal; dan/atau

h. Tata cara penggandengan dan penempelan dengan kendaraan lain.

Dalam huruf c Pasal di atas, mengatur bahwa setiap orang yang mengemudikan kendaraan bermotor dilarang menerobos APILL, tetapi dalam kenyataanya masih sangat banyak sekali suporter PSIM yang menerobos APILL. Maka sudah sangat jelas perbuatan mereka tersebut adalah sebagai pelanggaran lalu lintas.

f. Kendaraan Tidak Dilengkapi Dengan STNK

Selain kendaraan bermotor harus dilengkapi dengan tanda nomor kendaraan atau plat nomor. Kendaraan bermotor juga harus dilengkapi dengan Surat Tanda Nomor Kendaraan Bermotor. Dalam Pasal 68 ayat (1) Undang-undang Nomor 22 Tahun 2009 tentang Lalu Lintas dan Angkutan Jalan, menjelaskan:

"Setiap Kendaraan Bermotor yang dioperasikan di Jalan wajib dilengkapi dengan Surat Tanda Nomor Kendaraan Bermotor dan Tanda Nomor Kendaraan Bermotor".

Pasal tersebut menjelaskan bahwa setiap orang yang mengemudikan kendaraan bermotor di jalan, wajib dilengkapi dengan STNK, tidak terkecuali untuk para suporter PSIM. Maka jelas, jika kendaraan pengangkut suporter PSIM tidak dilengkapi dengan STNK, merupakan suatu pelanggaran lalu lintas.

g. Tidak Memakai Helm

Pasal 106 ayat (8) Undang-undang Nomor 22 Tahun 2009 tentang Lalu Lintas dan Angkutan Jalan, menjelaskan:

"Setiap orang yang mengemudikan Sepeda Motor dan Penumpang Sepeda Motor wajib mengenakan helm yang memenuhi standar nasional Indonesia".

Jenis pelanggaran tidak memakai helm ini, masih banyak dilakukan oleh para suporter PSIM yang memakai kendaraan bermotor jenis sepeda motor. Jika dilihat Pasal 106 ayat (8) yang sudah dijelaskan di atas, jelas suporter PSIM yang tidak memakai helm, meskipun beralasan antara Stadion Mandala Krida dan titik kumpul tidak begitu jauh, tetapi ia menggunakan kendaraan bermotor jenis sepeda motor dan dikemudikan di jalan, maka hal tersebut merupakan suatu pelanggaran lalu lintas. 
h. Berboncengan lebih dari 1 (satu) orang

Jenis pelanggaran ini seringkali dilakukan oleh suporter PSIM yang duduk di bangku sekolah. Rasa solidaritas yang masih kuat menyebabkan mereka berboncengan lebih dari 2 orang. Selain itu, tingkat pendidikan berlalu lintas yang masih rendah dapat menjadi faktor. Pasal 106 ayat (9) Undang-undang Nomor 22 Tahun 2009 tentang Lalu Lintas dan Angkutan Jalan, menjelaskan:

"Setiap orang yang mengemudikan Sepeda Motor tanpa kereta samping dilarang membawa Penumpang lebih dari 1 (satu) orang".

Dilihat dari Pasal tersebut, maka suporter PSIM yang mengemudikan sepeda motor dan membawa penumpang lebih dari 1 (satu) orang merupakan sebuah pelanggaran lalu lintas.

i. Membawa Bendera Berukuran Besar Yang Mengakibatkan Gangguan Konsentrasi Dalam Mengemudi Di Jalan

Pasal 106 ayat (1) Undang-undang Nomor 22 Tahun 2009 tentang Lalu Lintas dan Angkutan Jalan, menjelaskan:

"Setiap orang yang mengemudikan Kendaraan Bermotor di Jalan wajib mengemudikan kendaraannya dengan wajar dan penuh konsentrasi".

Faktanya masih terdapat suporter PSIM yang membawa bendera berukuran besar yang dapat mengganggu konsentrasi pengemudi lain di jalan. Dengan demikian sudah jelas, perbuatan yang mereka lakukan itu mengganggu konsentrasi pengendara lain sehingga dapat mengakibatkan kecelakaan lalu lintas yang disebabkan oleh suporter PSIM.

j. Bersikap Anarkis Di Jalan

Banyaknya masa suporter PSIM yang mengikuti konvoi, seringkali berbuat anarkis terhadap pengendara lainnya. Perbuatan anarkis yang mereka lakukan disebabkan karena pengendara lain yang bukan bagian dari suporter PSIM tidak mau memberikan jalannya kepada suporter PSIM. Perbuatan anarkis yang mereka lakukan contohnya, memukul-mukul kap mobil.

Jenis-jenis pelanggaran yang telah dijelaskan di atas, berakibat kepada pengguna jalan lainnya yang bukan bagian dari suporter PSIM. Pihak Satlantas mengatakan, perbuatan yang mereka lakukan itu jelas salah dan sangat mengganggu pengguna jalan lainnya yang bukan bagian dari suporter dan berakibat pada keamanan dan keselamatan lalu lintas dan angkutan jalan.

Dalam penegakan hukum yang dilakukan pihak kepolisian, sesuai dengan amanat Pasal 260 ayat (1) Undang-undang Nomor 22 Tahun 2009 tentang Lalu Lintas dan Angkutan Jalan, terkait kewenangan polisi lalu lintas. Maka upaya represif dan preventif yang dapat dilakukan, yaitu:

a. Upaya Represif

Upaya represif yang sejauh ini dilakukan oleh pihak Satlantas Polresta Yogyakarta dalam menanggulangi pelanggaran lalu lintas yang dilakukan oleh suporter PSIM di Kota Yogyakarta adalah:

\section{Penindakan Dengan Teguran}

Penindakan dengan teguran ini hanya diberikan kepada pelanggar lalu lintas yang berupa pemberhentian kendaraan, ketika melakukan pelanggarannya dapat dilihat secara kasat mata.

\section{Penindakan Dengan Tilang}

Penindakan dengan tilang merupakan langkah terakhir, apabila dengan teguran saja, si pelanggar tersebut masih mengulangi pelanggarannya kembali. Tilang hanya dapat dilakukan dengan cara mengikuti acara sidang di Kejaksaan.

Dalam upaya penegakan hukum secara represif, pihak kepolisian dapat menindak para pelaku dengan lebih tegas, di dalam Undang-undang Nomor 22 Tahun 2009 tentang Lalu Lintas dan Angkutan Jalan sudah jelas mengatur tentang tindakan yang mengganggu kenyamanan berkendara bagi pengguna jalan lain. 
Sejauh ini upaya represif yang telah disebutkan di atas telah dilaksanakan oleh pihak Satlantas Polresta Yogyakarta dalam menanggulangi pelanggaran lalu lintas yang dilakukan oleh kendaraan pengangkut supporter PSIM di Kota Yogyakarta.

b. Upaya Preventif

Upaya preventif di sini dilakukan oleh kedua pihak, yaitu pihak suporter PSIM dan pihak Satlantas Polresta Yogyakarta. Masing-masing pihak dalam melakukan upaya preventif-nya dapat dijelaskan sebagai berikut:

\section{Pihak Suporter PSIM Yogyakarta}

Satu hari sebelum pertandingan, pengurus suporter PSIM mengadakan rapat laskar dan memberikan briefing atau pengarahan kepada kelompok suporter PSIM yang akan berangkat ke Stadion Mandala Krida untuk tertib berlalu lintas dan tidak mencoreng nama baik suporter PSIM ketika ada yang di tindak akibat melanggar lalu lintas serta memberi peringatan untuk tidak mudah terpancing emosi dengan suporter lain ketika bertemu di jalan.

Pengurus suporter PSIM juga memberikan himbauan melalui media sosial, diantara lain Twitter: @Brajamusti_YK, Facebook: Info Brajamusti dan Instagram: @Brajamusti_YK, selain itu pengurus suporter PSIM juga mengadakan kerjasama dengan pihak panitia pelaksana dan kepolisian untuk melakukan razia baik di jalan dan di dalam stadion terhadap benda-benda yang dapat membahayakan orang lain.

\section{Pihak Satlantas Polresta Yogyakarta}

Pihak Satlantas Polresta Yogyakarta mempunyai 2 SOP tertentu terhadap suporter PSIM yang melakukan konvoi, SOP tersebut antara lain:

a) Melakukan pengawalan terhadap suporter yang melakukan konvoi. Pengawalan tersebut berguna agar semua rombongan suporter, baik berangkat maupun pulang, berjalan tertib, menyatu dan tidak saling berpencar yang dapat membuat kemacetan lalu lintas; dan

b) Menempatkan anggota Sabhara Lalu Lintas di titik-titik krusial yang dilalui suporter PSIM menuju Stadion Mandala Krida. Anggota yang berjaga di sekitar daerah tersebut lalu menyekat pintu-pintu masuk sekitar area Stadion Mandala Krida. Penyekatan tersebut digunakan untuk meminimalisir para suporter PSIM yang masih melakukan pelanggaran lalu lintas.

Satlantas Polresta Yogyakarta sudah melaksanakan kedua upaya preventif yang telah dijelaskan di atas namun belum sepenuhnya berhasil. Untuk mewujudkan upaya preventif, masih dinilai sulit karena banyak suporter PSIM yang tidak peduli akan hukum berlalu lintas dan masih banyak yang duduk di bangku sekolah.

Ketentuan Pasal 106 ayat (4) Undang-undang Nomor 22 Tahun 2009 tentang Lalu Lintas dan Angkutan Jalan, menjelaskan:

Setiap orang yang mengemudikan Kendaraan Bermotor di Jalan wajib memenuhi ketentuan:

a. Rambu perintah atau rambu larangan;

b. Marka jalan;

c. Alat Pemberi Isyarat Lalu Lintas;

d. Gerakan Lalu Lintas;

e. Berhenti dan Parkir;

f. Peringatan dengan bunyi dan sinar;

g. Kecepatan maksimal atau minimal; dan/atau

h. Tata cara penggandengan dan penempatan dengan Kendaraan lain.

Ketentuan Pasal yang telah disebutkan di atas sudah sangat jelas namun masih ada suporter PSIM yang melanggar. Seharusnya peraturan tersebut dipatuhi oleh semua orang yang mengemudikan 
kendaraan bermotor di jalan, tidak terkecuali suporter PSIM demi keselamatan pengguna kendaraan lain dan untuk suporter PSIM itu sendiri.

Tujuan mengenai diselenggarakannya lalu lintas telah diatur di dalam Pasal 3 Undang-undang Nomor 22 Tahun 2009 tentang Lalu Lintas dan Angkutan Jalan, yang menjelaskan:

Lalu lintas dan Angkutan Jalan diselenggarakan dengan tujuan:

a. Terwujudnya pelayanan Lalu Lintas dan Angkutan Jalan yang aman, sehat, selamat, tertib lancar, dan terpadu dengan moda angkutan lain untuk mendorong perekonomian nasional, memajukan kesejahteraan umum, memperkukuh persatuan dan kesatuan bangsa, serta mampu menjunjung tinggi martabat bangsa;

b. Terwujudnya etika berlalu lintas dan budaya bangsa; dan

c. Terwujudnya penegakan hukum dan kepastian hukum bagi masyarakat.

Berdasarkan tujuan yang telah dijelaskan di atas, negara bertanggung jawab atas penertiban Lalu Lintas dan Angkutan Jalan serta pembinaannya dilaksanakan oleh Pemerintah Kota Yogyakarta sesuai dengan apa yang tercantum di dalam BAB IV Undang-undang Nomor 22 Tahun 2009 tentang Lalu Lintas dan Angkutan Jalan.

Saat ini penegakan hukum yang dilakukan di jalan Kota Yogyakarta dengan tindakan preventif perlu ditingkatkan lagi. Tindakan preventif yang dilakukan Satlantas Polresta Yogyakarta dapat dilakukan dengan cara memberikan pengetahuan tentang lalu lintas sejak bangku sekolah, mulai dari usia SD hingga SMA. Karena tidak dapat dipungkiri bahwa suporter PSIM yang melakukan pelanggaran lalu lintas kebanyakan merupakan pelajar yang masih duduk di bangku sekolah. Untuk itu memberikan penyuluhan-penyuluhan tertib berlalu lintas merupakan hal yang wajib diterapkan sejak di bangku sekolah.

\section{Simpulan}

Berdasarkan penjelasan sebelumnya mengenai penegakan hukum terhadap pelanggaran lalu lintas oleh kendaraan pengangkut suporter PSIM, maka dapat diambil kesimpulan sebagai berikut:

Upaya represif yang dilakukan pihak Satlantas Polresta Yogyakarta ada 2 (dua) cara, yaitu:

a. Penindakan dengan teguran, diberikan ketika pelanggar lalu lintas melakukan jenis pelanggaran yang dapat dilihat secara kasat mata.

b. Penindakan dengan tilang, merupakan upaya terakhir apabila dengan teguran saja, si pelanggar tersebut masih mengulanginya kembali. Yogyakarta.

Upaya preventif dilakukan oleh 2 (dua) pihak. Pihak suporter PSIM dan pihak Satlantas Polresta

a. Pihak suporter PSIM biasanya 1 (satu) hari sebelum pertandingan mengadakan rapat laskar yang bertujuan untuk menghimbau agar tertib berlalu lintas di jalan. Pengurus juga memperingati agar tidak mudah terpancing emosinya ketika bertemu dengan suporter dari tim lain di jalan.

b. Pihak Satlantas Polresta Yogyakarta biasanya melakukan pengawalan terhadap suporter yang konvoi-konvoi, tujuannya agar rombongan konvoi tersebut tidak membuat kemacetan lalu lintas, serta menempatkan anggota-anggota yang lain di titik-titik ramai yang dilalui suporter PSIM menuju Stadion Mandala Krida. 
Pusat Kajian Hukum Pidana dan Kriminologi

Fakultas Hukum, Universitas Muhammadiyah Yogyakarta

E-mail: ijclc@umy.university

\section{Daftar Pustaka}

\section{Buku}

Cotterrell, Roger. (2016). Sosiologi Hukum. Bandung: Nusa Media.

Islafatun, Nor. (2014). Arek Bonek: Satu Hati Untuk Persebaya. Yogyakarta: Notebook.

Soekanto, Soerjono. (1982). Kesadaran Hukum dan Kepatuhan Hukum. Jakarta: Cv Rajawali.

Wahyudi, Hari. (2009). The Land of Hooligans. Jogjakarta: Garasi.

\section{Jurnal}

Hapsari, Indria dan Wibowo Istiqomah. (2015). Fanatisme Dan Agresivitas Supporter Klub Sepak Bola. Jurnal Psikologi, 8(1), ISSN: 2086-3047

\section{Peraturan Perundang-undangan}

Undang-undang Dasar Negara Republik Indonesia Tahun 1945.

Kitab Undang-undang Hukum Pidana.

Undang-undang No. 8 Tahun 1981 Tentang Hukum Acara Pidana.

Undang-undang No. 2 Tahun 2002 Tentang Kepolisian Negara Republik Indonesia.

Undang-undang No. 22 Tahun 2009 Tentang Lalu Lintas dan Angkutan Jalan.

Peraturan Pemerintah No. 79 Tahun 2013 Tentang Jaringan Lalu Lintas dan Angkutan Jalan.

Peraturan Menteri No. 13 Tahun 2014 Tentang Rambu Lalu Lintas.

\section{Website}

Tirto.id, Ricuh PSIM vs Persis: Menjalar ke Prambanan, Wartawan Jadi Korban, 13 November 2019, https://bit.ly/39dArDP, (20:44). 